\title{
Capture of images in inaccessible areas in an underground mine using an unmanned aerial vehicle
}

\author{
GR Freire AngloGold Ashanti Ltd, Brazil \\ RF Cota AngloGold Ashanti Ltd, Brazil
}

\begin{abstract}
Underground operation is a complex mining method where safety, stability, and ore recovery issues, among other factors, could be an obstacle to operations. In most cases, a simple review of the site could help engineers to understand and solve the problems. To create this overview, many types of images captured were considered. The non-entry mining method used at Cuiabá mine does not allow people to enter the stopes after blasting. The only way to obtain images after blasting is by using drones or other unmanned aerial vehicles (UAVs) fitted with cameras. The difficulties for this type of project include lighting, high-definition image capture, and access. Remote access in areas mined by the sublevel method at the Cuiabá mine is only possible with a UAV that is equipped with technology that can film with effective illumination. In addition, the equipment should be able to fly without the aid of GPS, fly at variable low speed to withstand small shocks with the rock wall and support elements, and often fly without visual contact with the pilot. Furthermore, the UAV controls must be easy enough for mine site employees to use with limited training and knowledge of aeronautics. For this purpose, a hybrid equipment was designed, using a helium gas filled balloon, with remote controlled quadcopter propellers, powerful LED lighting, rechargeable batteries, remote controlled cameras, image stabiliser, and radio frequency transmitters for control and image visualisation. A number of other solutions have been customised in the device to avoid problems inherent in mine operation. In countless trails, the UAV presented images that helped the local team change projects, reconsider pillar sizes, find ore trapped inside the stopes, and identify other important situations allowing an increase in safety and production.
\end{abstract}

Keywords: unmanned aerial vehicles, non-entry mining method, images, safety, remote access

\section{Introduction}

AngloGold Ashanti's Cuiabá mine is using sublevel stoping as the main mining method for gold extraction (Freire 2016). In spite of the high productivity of this method, in some stopes with complex geometry, several stability and recovery problems are common, which are difficult to understand, even with the use of $3 \mathrm{D}$ cavity monitoring surveys (CMS) undertaken for the reconciliation of mined stopes. These problems may be due to poor blasting, poor free faces, drillhole deviations with holes entering the hanging wall, etc. Other factors that may influence production are the poor design of stope floor angles resulting in ore not sliding down the footwall, and thus being left behind (ore loss). In order to understand some of the causes and/or results of these issues, it is important to observe all areas of the open stope. As stope access is impossible because there is no support or scaling of the backs and walls after blasting, methods of remote image capture were studied, which allows observation of the localised details using large panoramic images of the boundary of the excavations.

\subsection{Context}

When searching for solutions for remote filming in inaccessible areas began, drones were considered, as it is an accessible, easy-to-use technology with no need for customisation. Numerous underground tests were conducted and the equipment tested did not show good results, mainly in the areas of lighting and navigability. The drone could not carry the payload of lights needed to illuminate an entire stope and retain 
the battery life to sustain itself in flight. As for navigability, drones use GPS to facilitate operating conditions, but underground use of GPS data is impossible (Macedo, pers. comm., 2015).

Drone testing inside the mine was carried out in an illuminated drift at Level 9 of Cuiabá mine with drive dimensions $(5.5 \times 5.5 \mathrm{~m})$. The pilot who conducted the tests had three years of drone experience and more than 20 years' experience with aeromodelling. Even with the experienced pilot and new equipment, the operation was extremely difficult and the camera did not take good quality images with local lighting (Figures 1 and 2).

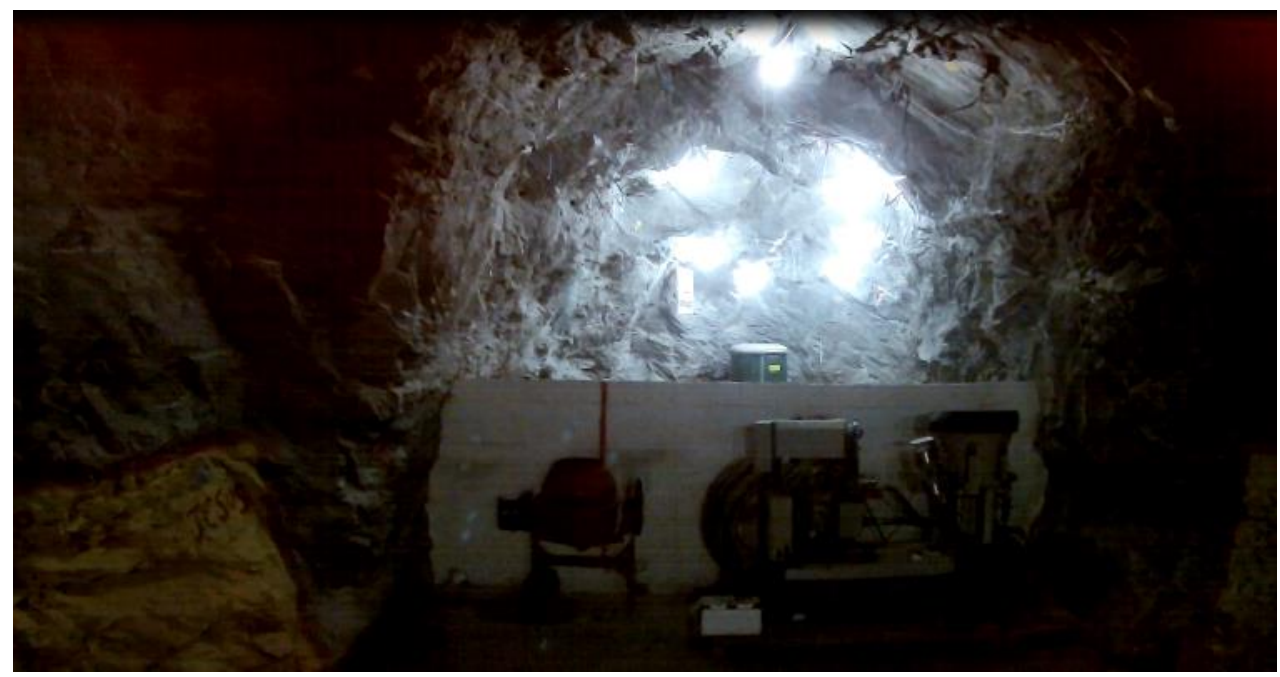

Figure 1 Image from the drone, in a gallery inside the mine

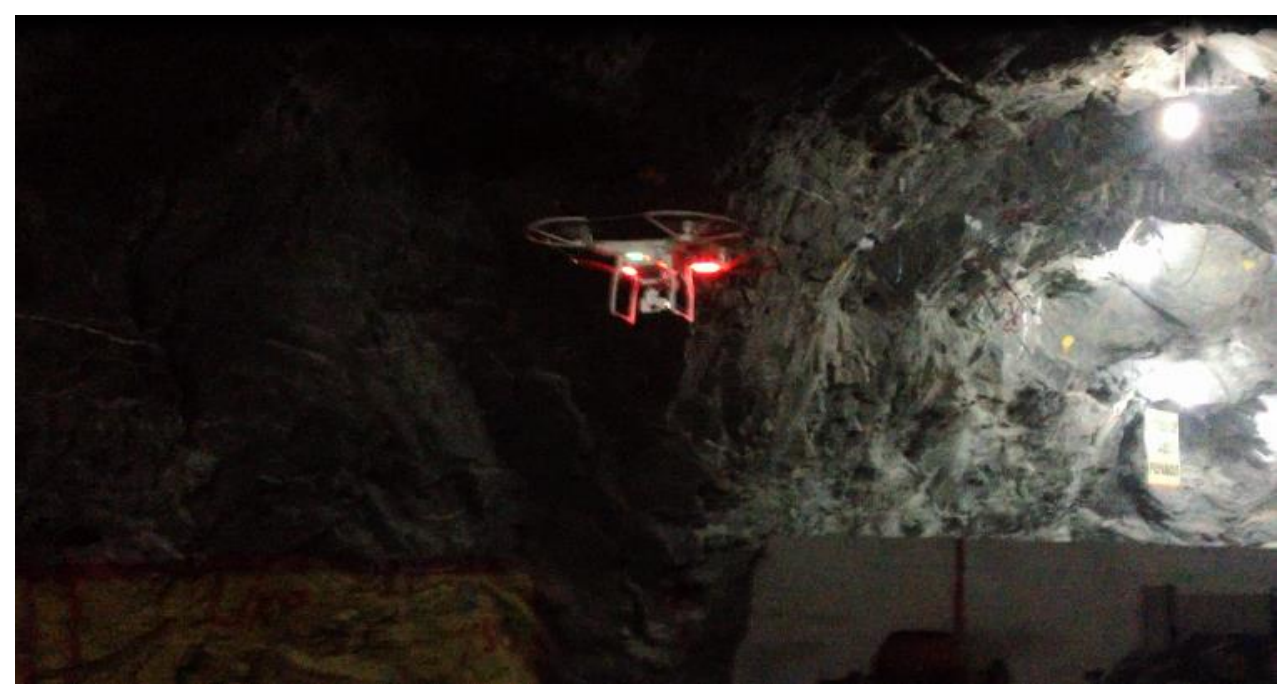

Figure 2 Drone capturing images in a gallery inside the mine

\section{Zeppelin project conception}

After drone testing at the mine, the limitations of the device coupled with the constraints of the underground operation resulted in a list of minimum requirements. It was determined that a new device should have the following characteristics: ability to be remotely controlled, propulsion using electric power (batteries), and be able to capture high-definition images with real-time transmission. However, unlike the drone, it must move at low speed, be able to withstand collisions with the rock and support without affecting the device or flight, and have the capacity to carry on-board lighting. Specifically, it should be easy to pilot in underground environments by the company's own technical team. 
With the knowledge acquired from drone testing, a helium gas balloon manufacturer was engaged to design a hybrid device that manages the previously identified obstacles. After an underground site visit from the supplier (Queiroz, pers. comm., 2015), a draft was submitted detailing how such an unmanned aerial vehicle (UAV) should be constructed:

- A balloon that can carry all on-board technology.

- High-definition camera with stabilisation.

- Batteries.

- A multi-directional propeller.

- A tail rotor.

- Sufficient light capability to illuminate a whole stope.

- Transmitters for video and controls.

The device (Zeppelin) of the required size was built and optimised for balancing and payload capability, while maintaining ease of control inside the drifts (Figure 3).

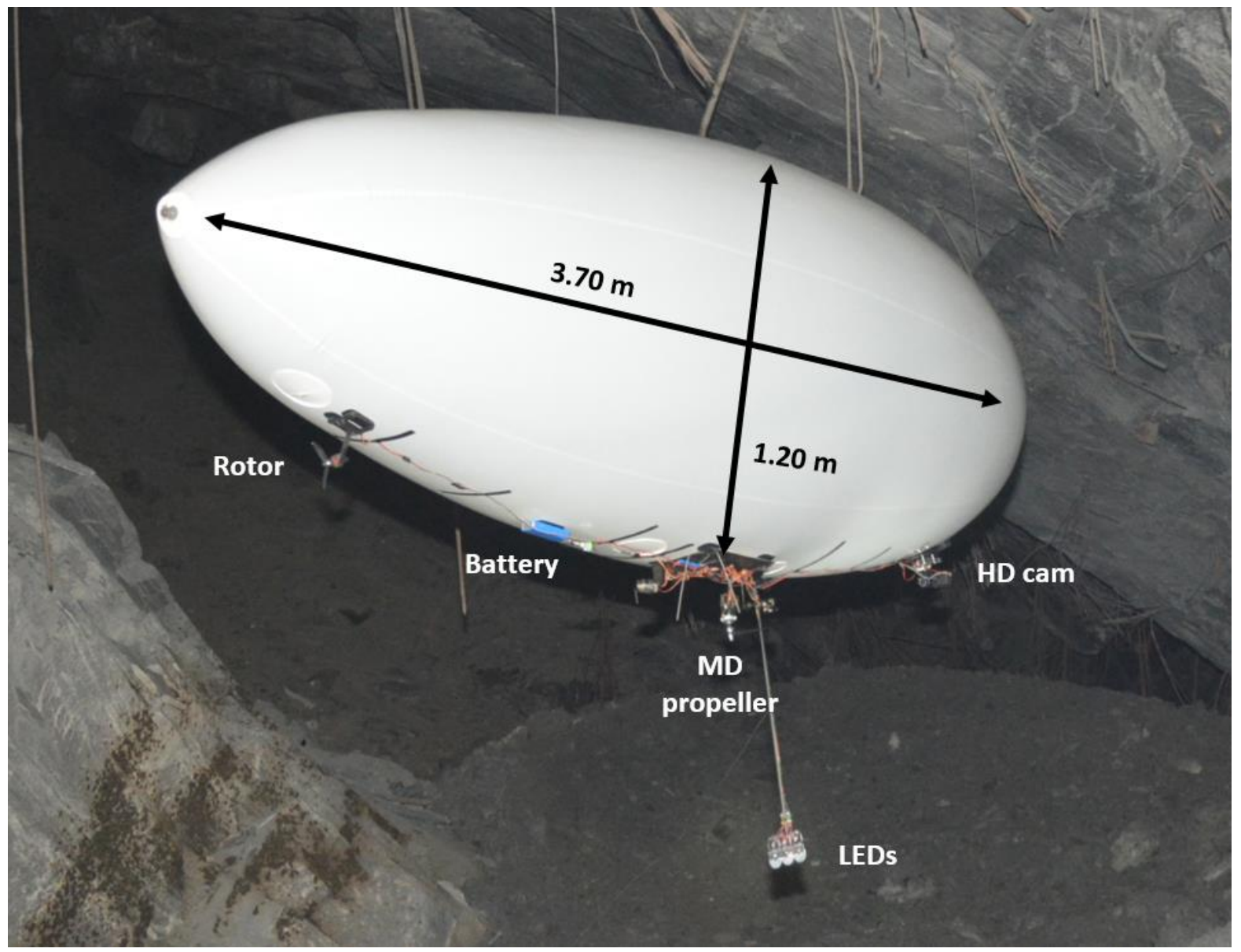

Figure 3 First prototype flying inside the Cuiabá mine, with the main features indicated

\section{Trial flights}

The first test at the mine was carried out in a sublevel stope, with a width of 5-6 m, dipping $45^{\circ}$ and $20 \mathrm{~m}$ between sublevels. The on-board illumination was enough to show in detail the rock walls, rock mass structures, evidence of blasting, and support units (Figure 4). Furthermore, the capacity of the remote control was tested, without direct view with the balloon, with only the laptop screen for monitoring (Figure 5). 

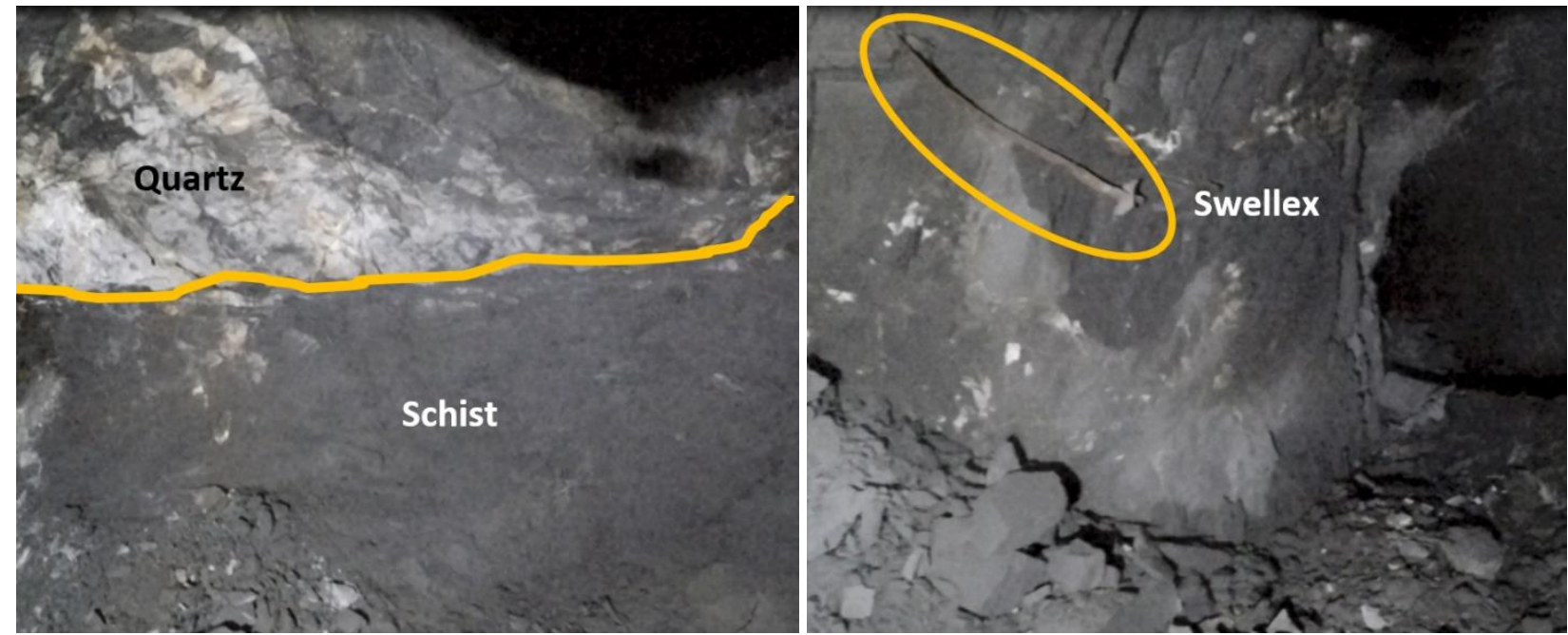

Figure 4 (a) Rock mass (contact zone); (b) Support (Swellex bolts)
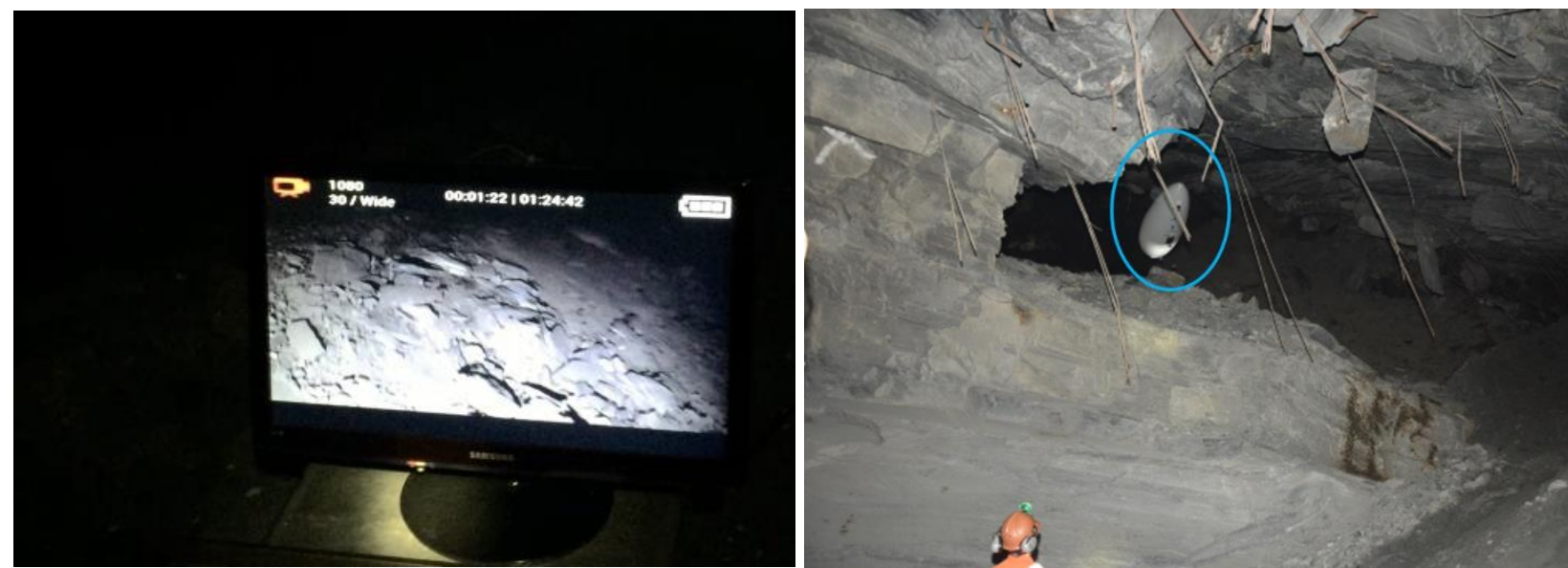

Figure 5 (a) Remote monitoring screen; (b) Zeppelin disappearing inside the stope

Finally, more LED plates were added to increase the illumination and improved antennas were used so that there is no signal loss during flights when the direct view of the balloon is lost (Figure 6).

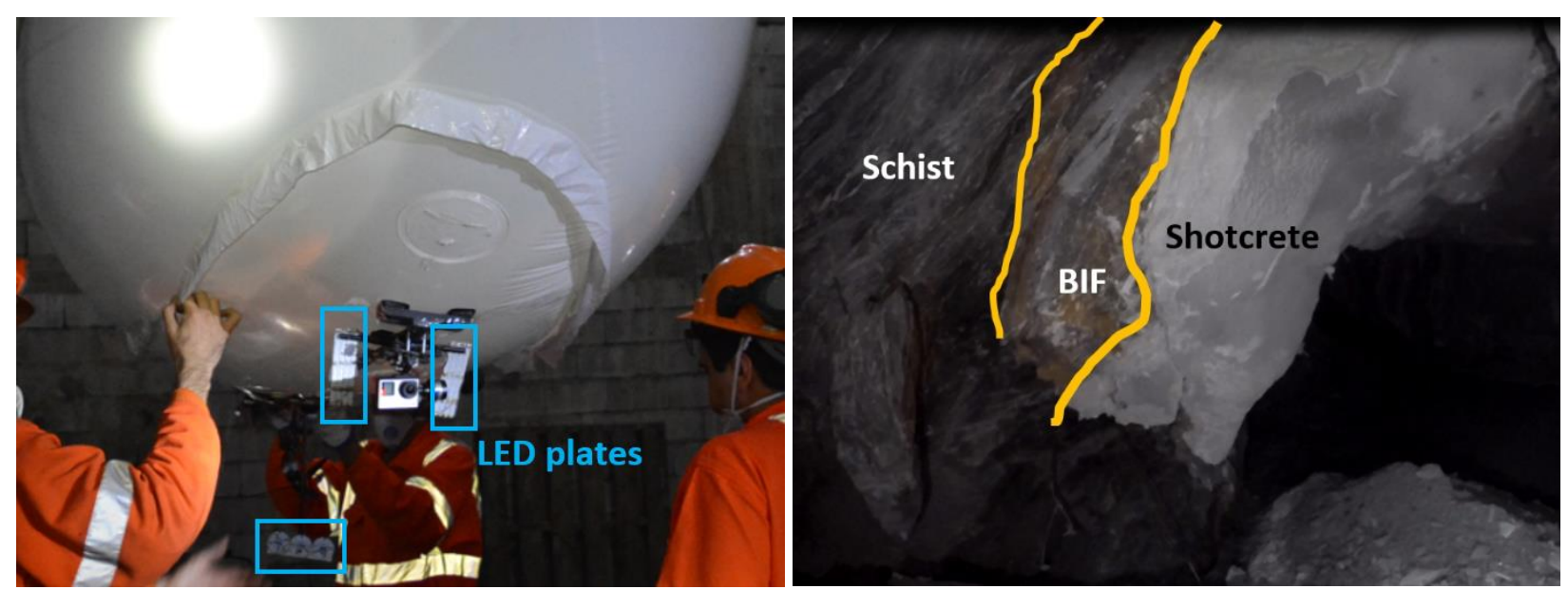

Figure 6 (a) Final version of the Zeppelin; (b) Image with more illumination and detail 


\section{$4 \quad$ Using the UAV}

The Zeppelin was able to capture all the information required according to the initial scope of the project. In this section, it will be demonstrated how the information obtained was used to make important decisions at the mine. In this case, a stope was presented with low overbreak and underbreak, mined in a region with failure of the sill pillar. A prominent fault was identified that may affect the stability of the regional pillar (Figure 8). Despite the good results from the CMS, showing no underbreak, the amount of ore blasted was not retrieved from the stope. According to the Zeppelin images, the blasting was done well, considering the integrity of the hanging wall, footwall and 'half barrels' (Figure 7). It was clearly seen that ore remained on the footwall in some areas, explaining the loss of blasted ore (Figure 8). For the next stages stope mining, the dip of the footwall and the drill and blast designs will be reassessed to ensure that blasted material rills down the footwall.
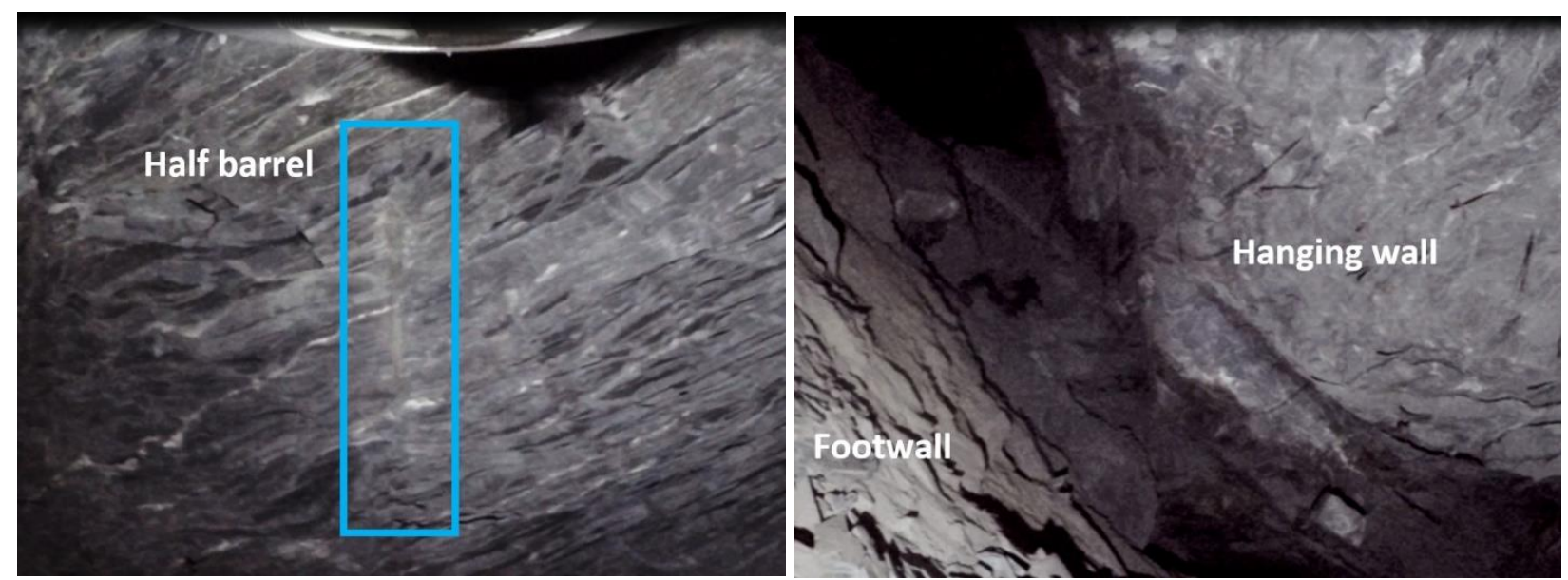

Figure 7 (a) Half barrel in the hanging wall; (b) Intact hanging wall with cables and the ore on the footwall

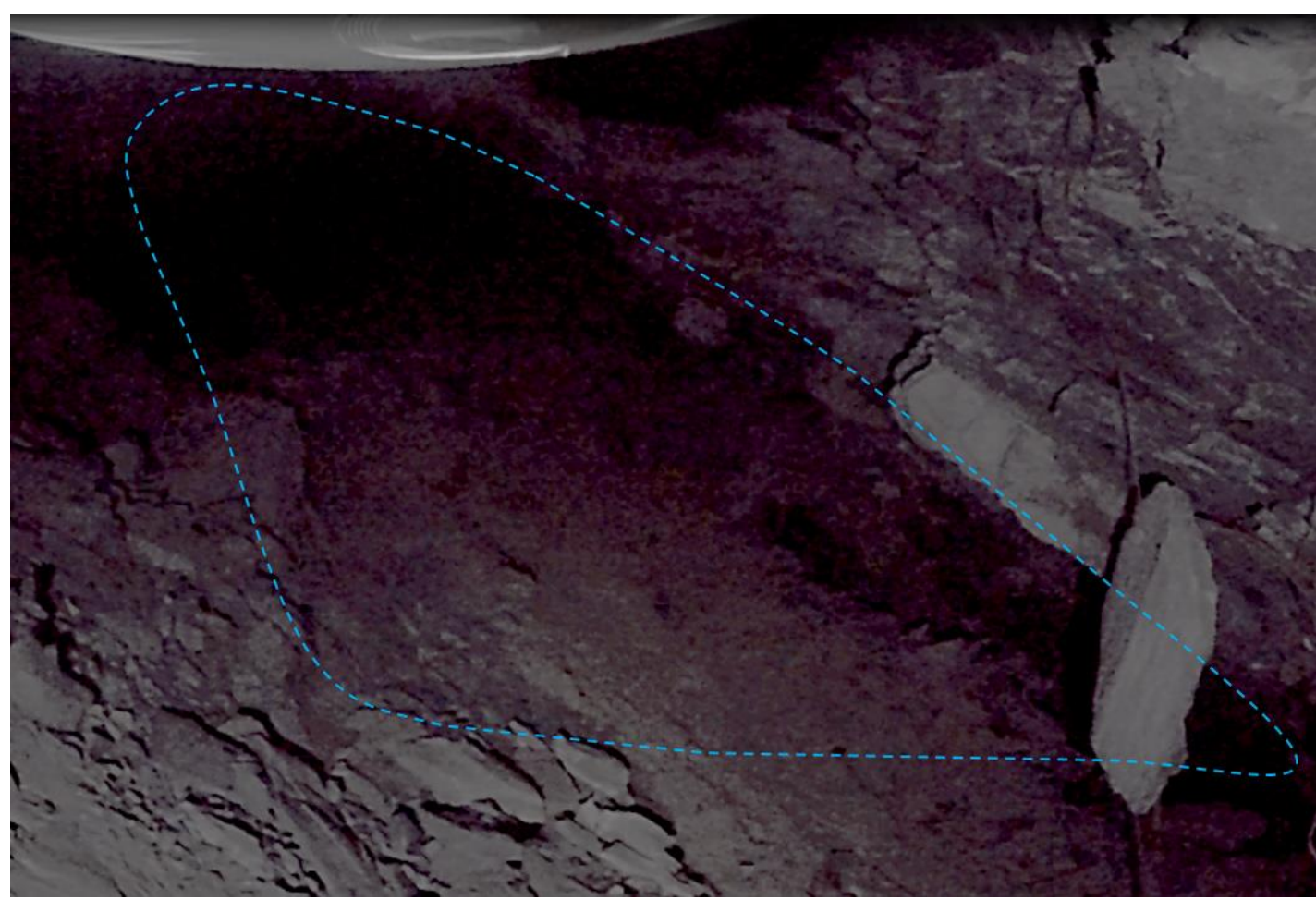

Figure 8 Snapshot from a video recorded inside the stope showing the ore trapped on the footwall 
Finally, the images show clearly the fault in the sill pillar and that, locally, there was no collapse of the pillar (Figure 9).

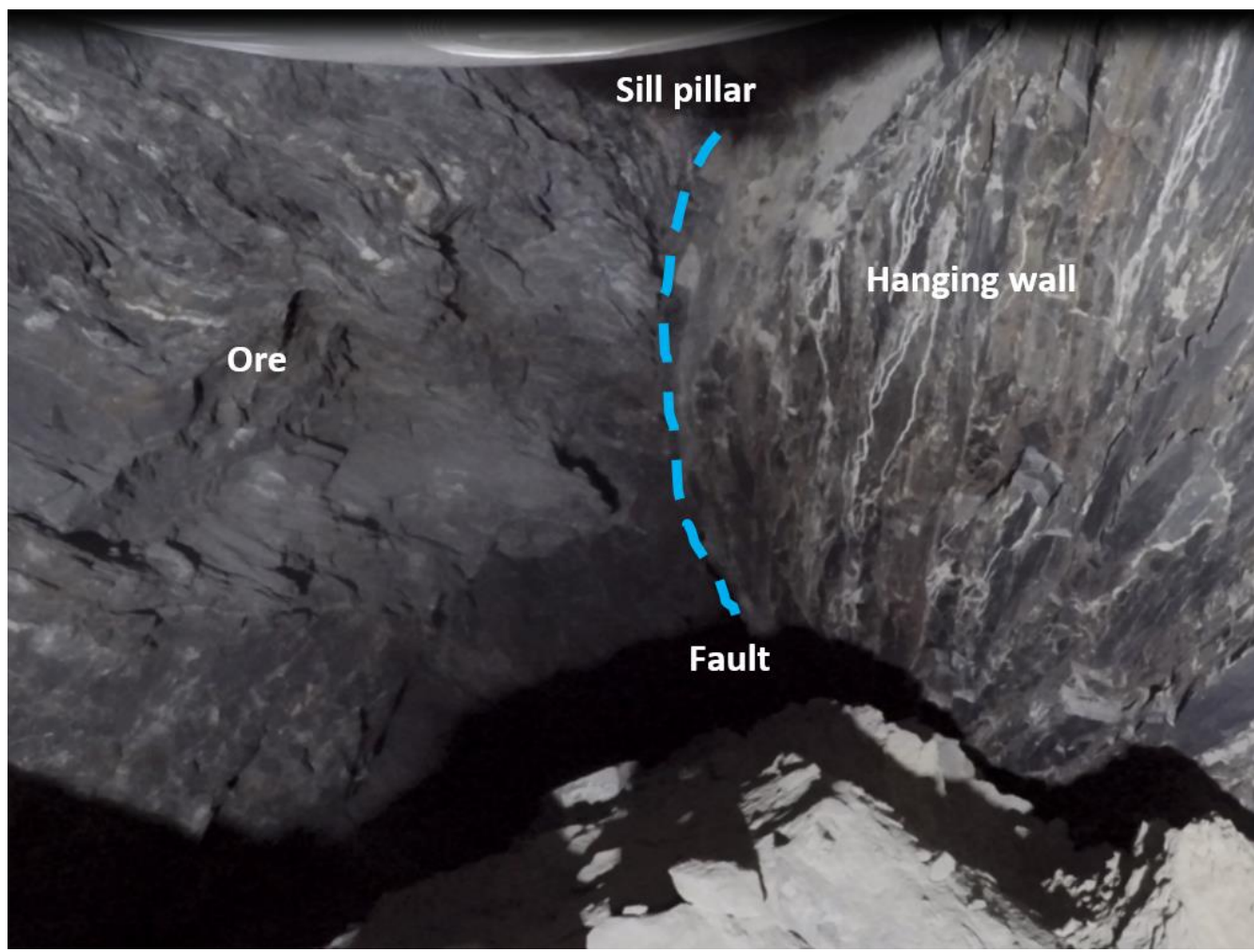

Figure 9 Snapshot from a video recorded inside the stope show the sill pillar with no collapse

\section{Conclusion}

With this equipment in operation, it was possible to carry out a scan in one of the main stopes with ground control and operational issues. It was possible to identify the root causes of the problems and avoid several of them in the future. It was possible to revise the designs that may have required the increase of pillar sizes or changes in stope geometries. This method can complement other monitoring methods employed at the mine such as borehole camera images to identify deviation and detailed studies of the effects of the geological structures in the rib pillars and sill pillar.

In addition to safely inspecting and monitoring inside non-entry areas, not only production stopes, but potentially shafts and other inaccessible areas, the information collected by the device is used to make important decisions on the continuity of the mining in each stope and the calculation of the pillars and support elements. With the potential recovery of lost ore, it is estimated that the capital expenditure is easily offset (up to 40,000 times) against the potential loss of ore in $1 \mathrm{~m}$ of sill pillar.

\section{Acknowledgement}

The authors thank AngloGold Ashanti for funding the project and making the data available. Technical support was provided by the mine's rock mechanics team. The authors also thank Álvaro Pidde Queiroz for the partnership in the conception and realisation of the project.

\section{References}

Freire, GR 2016, 'Analysis of the top down and bottom up methods and their effects on the deepening of the Cuiabá mine, Sabará-MG', Proceedings of the VII Brazilian Symposium on Rock Mechanics, International Society for Rock Mechanics, Lisbon. 